\title{
The Slow Afterhyperpolarization in Hippocampal CA1 Neurons Covaries with Spatial Learning Ability in Aged Fisher 344 Rats
}

\author{
Geoffrey C. Tombaugh, Wayne B. Rowe, and Gregory M. Rose \\ Memory Pharmaceuticals Corporation, Montvale, New Jersey 07645
}

\begin{abstract}
Rodents commonly exhibit age-related impairments in spatial learning tasks, deficits widely thought to reflect cellular or synaptic dysfunction in the hippocampus. Using whole-cell recordings, we examined the afterhyperpolarization (AHP) in CA1 pyramidal cells in hippocampal slices from young (4-6 months of age) and aged (24-26 months of age) Fisher 344 male rats that had been behaviorally characterized in the Morris water maze. The slow AHP (sAHP) recorded from learning-impaired aged rats (AI) was significantly larger than that seen in either age-matched unimpaired rats or young controls. Among aged rats, sAHP amplitude was inversely correlated with both acquisition and probe performance in the water maze. Action potential parameters among the three groups were similar, except for spike accommodation, which was more pronounced in the AI group. Intracellular application of the cAMP analog 8-CPT-cAMP suppressed the SAHP but failed to reveal any age- or performance-related differences in the medium AHP. 8-CPT-cAMP abolished the age-related difference in spike accommodation, whereas instantaneous firing frequency was unchanged. Calcium spikes were of similar amplitude in all three groups but were broader and had significantly larger tails in aged rats; these age-related changes could be mimicked in young neurons after exposure to BayK8644. The calcium spike among aged rats correlated with task acquisition in the maze but, unlike the sAHP, failed to correlate with probe performance. This is the first demonstration that sAHP amplitude covaries with spatial learning ability in aged rats, implying that CA1 excitability strongly influences certain aspects of cognitive function. Our findings also indicate that multiple processes, in addition to elevated calcium influx, conspire to induce cognitive decline during aging.
\end{abstract}

Key words: hippocampus; aging; AHP; excitability; spatial learning; calcium

\section{Introduction}

Rats are highly skilled at learning and remembering tasks that depend on contextual cues. During aging, this ability declines dramatically in many, although not all, subjects (Gage et al., 1984; Barnes and McNaughton, 1985; Deupree et al., 1991; Quirion et al., 1995; Backman et al., 1996). The basis for this variability is unknown, but because the hippocampus is essential for spatial learning and certain aspects of contextual learning (Morris et al., 1982, 1990; Holland and Bouton, 1999; Hollup et al., 2001), an intensive search continues in this brain region for the cause of age-related cognitive decline.

It is now clear that age-related spatial learning deficits in rats do not arise from hippocampal cell or synapse loss (Rapp and Gallagher, 1996; Geinisman et al., 2004), implying that functional rather than structural changes are involved (Rapp et al., 1999; Smith et al., 2000). Numerous models have attempted to explain age-related cognitive decline: increased L-type calcium channel expression, blunted NMDA receptor activity, and enhanced postsynaptic phosphatase activity are a few examples (Campbell

\footnotetext{
Received Sept. 10, 2004; revised Jan. 25, 2005; accepted Jan. 26, 2005. We thank Philip Landfield for critical reading of this manuscript.

Correspondence should be addressed to Dr. Geoffrey C. Tombaugh, Memory Pharmaceuticals Corporation, 100 Philips Parkway, Montvale, NJ 07645. E-mail: tombaugh@memorypharma.com. DOI:10.1523/JNEUROSCI.5023-04.2005

Copyright $\odot 2005$ Society for Neuroscience $\quad$ 0270-6474/05/252609-08\$15.00/0
}

et al., 1996; Landfield, 1996; Norris et al., 1998a,b; Eckles-Smith et al., 2000; Clayton and Browning, 2001; Foster et al., 2001).

Among these models, the calcium hypothesis of aging has perhaps received the most attention. According to this hypothesis, elevated calcium influx through L-type channels impairs cognition, at least in part, by activating $\mathrm{Ca}^{2+}$-dependent $\mathrm{K}^{+}$channels that underlie the slow afterhyperpolarization (sAHP) in CA1 neurons (Landfield and Pitler, 1984; Moyer et al., 1992; Disterhoft et al., 1996; Marrion and Tavalin, 1998; Bowden et al., 2001). An enlarged sAHP might interfere with spatial learning by blunting synaptic integration or by elevating the threshold for burst firing in CA1 neurons (Azouz et al., 1996), an event that occurs at theta frequencies during exploratory behavior (Otto et al., 1991) and is required for long-term potentiation (LTP) induction by theta-frequency stimulation in vitro (Thomas et al., 1998; Pike et al., 1999; Paulsen and Sejnowski, 2000). In support of this idea, LTP triggered by theta-frequency stimulation is reduced in CA1 of spatially impaired rats (Tombaugh et al., 2002).

Despite the finding that L-type currents increase with age, L-type channel blockers reduce the sAHP in young and aged rabbit CA1 neurons by a proportionally similar amount (Power et al., 2001). Moreover, muscarinic agonists can reverse ageassociated deficits in rabbit eye-blink conditioning while they depress the sAHP in CA1 via a $\mathrm{Ca}^{2+}$-independent mechanism (Weiss et al., 2000). Such findings raise questions about whether 
enhanced calcium influx per se underlies learning deficits in aged animals, while they point to the sAHP as a more proximal factor (Giese et al., 2001).

To date, the relationships among the sAHP, calcium influx, and hippocampal-dependent behavior have been evaluated most extensively in rabbits subjected to eye-blink conditioning, but these measures have never been related to one another in the same study. If sAHP enhancement is a key determinant of agerelated deficits in hippocampal-based learning, then this linkage should generalize to other hippocampal-dependent tasks and across species. The goal of our study was to test this idea directly in behaviorally characterized aged rats using the Morris water maze and to scrutinize the putative link between calcium influx and age-related cognitive decline.

\section{Materials and Methods}

Animals. Young (4-6 months of age) and aged (24-26 months of age) male Fisher 344 (F344) rats were obtained from Hilltop Lab Animals (Scottsdale, PA). The animals were left undisturbed for a minimum of 1 month in our facility until the beginning of behavioral testing. Rats were housed in pairs in polycarbonate cages $(45 \times 30 \times 18 \mathrm{~cm})$ with corncob bedding and maintained on a $12 \mathrm{~h}$ light/dark schedule (lights off at 7:00 P.M.). Food (LabDiet 5001 rodent diet; LabDiet, Brentwood, MO) and water were available ad libitum. Animal health was monitored by a veterinarian; animals showing overt signs of morbidity were removed from the study. All procedures were conducted in accordance with local Institutional Animal Care and Use Committee guidelines.

Behavior. Two cohorts of young and aged rats were characterized in the Morris water maze as described previously (Tombaugh et al., 2002). The maze consisted of a 1.6-m-diameter circular pool filled to within $15 \mathrm{~cm}$ of the rim with water $\left(22^{\circ} \mathrm{C}\right)$ made opaque by the addition of nontoxic white latex paint (Createx Colors, East Granby, CT). A circular Plexiglas escape platform ( $14.5 \mathrm{~cm}$ in diameter) was located in the center of one of the quadrants of the pool. The animals were given 15 trials over 5 consecutive days with the platform submerged $2 \mathrm{~cm}$ below the surface of the water (three trials per day; $120 \mathrm{~s}$ maximum trial duration; 20-30 min intertrial interval). On the last training trial, a probe test was performed in which the retractable Plexiglas platform was pneumatically lowered out of reach of the rats for $30 \mathrm{~s}$ and then returned to its original position for the remainder of the trial. The total dwell time in and mean distance from a 40-cm-diameter target zone (annulus-40) around the platform center was used to assess probe performance. All latency, distance, and dwell-time measures were recorded and analyzed using a computerbased tracking system (San Diego Instruments, San Diego, CA). On day 6 , rats were given four $60 \mathrm{~s}$ trials in which the platform was raised $2.5 \mathrm{~cm}$ above the water level to test for visual, motivational, or motor deficits that may have influenced performance. Rats that required $>40$ s to reach the visible platform on any trial were excluded from further analysis.

The cognitive status of an aged animal was defined on the basis of its latencies to find the submerged platform on days $3-5$ of testing relative to the mean latency of young controls (see Fig. 1). An aged impaired (AI) rat was defined as one whose mean latency (across days 3-5 of testing) differed by $>3.0$ SDs from that of young controls (Y). An aged animal was considered unimpaired (AU) if its mean latency score was $\leq 0.5 \mathrm{SD}$ from the mean of the young controls. Aged animals whose mean escape latencies fell between these values were not used in any additional tests (Tombaugh et al., 2002).

Electrophysiology. Parasagittal hippocampal slices $(300 \mu \mathrm{m})$ from young (4-6 months of age) and aged (24-26 months of age) male F344 rats were prepared with a vibratome at $4^{\circ} \mathrm{C}$, warmed to $36^{\circ} \mathrm{C}$ for $1 \mathrm{~h}$, held at room temperature, and transferred as needed to a submerged chamber $\left(30^{\circ} \mathrm{C}\right.$ ) perfused at $2 \mathrm{ml} / \mathrm{min}$ with the following (in $\mathrm{mM}$ ): $124 \mathrm{NaCl}, 4.5$ $\mathrm{KCl}, 1 \mathrm{NaH}_{2} \mathrm{PO}_{4}, 26 \mathrm{NaHCO}_{3}, 2.5 \mathrm{CaCl}_{2}, 1.3 \mathrm{MgCl}_{2}$, and 10 glucose. Aged tissue was sliced in a solution in which $\mathrm{NaCl}$ was replaced by 110 mu sucrose and $\mathrm{CaCl}_{2}$ was reduced to $0.1 \mathrm{~mm}$ (Moyer and Brown, 1998). Slice preparation occurred after the following intervals from the last visible probe trial: $\mathrm{Y}, 25 \pm 8 \mathrm{~d}$; $\mathrm{AU}, 13 \pm 4 \mathrm{~d}$; $\mathrm{AI}, 30 \pm 5 \mathrm{~d}$. CA1 pyramidal cells were visualized by infrared-differential interference contrast, and whole-cell current-clamp recordings were made with a Multiclamp 700B amplifier (Axon Instruments, Union City, CA) using pipettes (4-7 M $\Omega$ ) containing the following (in $\mathrm{mm}$ ): $135 \mathrm{~K}$-methylsulfate, $5 \mathrm{NaCl}, 10$ HEPES, 0.1 EGTA, $1 \mathrm{MgCl}_{2}, 2 \mathrm{Na}_{2}$-ATP, and $0.3 \mathrm{Na}-\mathrm{GTP}$, pH adjusted to 7.2. AHPs were evoked from the resting potential of the cell or from -50 $\mathrm{mV}$ by applying either (1) a $50 \mathrm{~ms}$ depolarizing current pulse of sufficient amplitude (300-1000 pA) to evoke four overshooting spikes or (2) a train of $4 \times 2 \mathrm{~ms}, 1.5 \mathrm{nA}$ pulses applied at $15 \mathrm{~ms}$ intervals. For medium AHP (mAHP) measurements, $50 \mu \mathrm{M} 8$ 8-CPT-cAMP, a cAMP analog, was added to the pipette solution to suppress the sAHP. Cells with an initial resting membrane potential (RMP) more depolarized than $-55 \mathrm{mV}$ were excluded from analysis. SAHP amplitude was defined as the mean value of the membrane potential within a $100 \mathrm{~ms}$ window occurring $400-500 \mathrm{~ms}$ after the end of the depolarizing current pulse. Cell firing was assessed with $800 \mathrm{~ms}$ depolarizing current pulses. Accommodation was measured by counting the number of spikes during the pulse; an instantaneous firing frequency was calculated for the first four interspike intervals evoked by a fixed $350 \mathrm{pA}$ current pulse.

For calcium spike recording, pipettes were filled with a solution in which Cs-methanesulfonate replaced K-methylsulfate and $0.5 \mu \mathrm{M}$ TTX was added to the bath. The delay interval for slice preparation was as follows: Y, $15 \pm 3 \mathrm{~d}$; AU, $12 \pm 4 \mathrm{~d}$; AI, $27 \pm 8 \mathrm{~d}$. Calcium spikes were recorded between 5 and $10 \mathrm{~min}$ after patch rupture to normalize the influence of any time-dependent changes (i.e., "rundown") on calcium channel activity (Y, 6.1 $\pm 0.4 \mathrm{~min}$; AU, $7.1 \pm 0.3 \mathrm{~min}$; AI, $6.2 \pm 0.3 \mathrm{~min}$ ). Calcium spikes were evoked by a $50 \mathrm{~ms}$ depolarizing current pulse with an amplitude $100 \mathrm{pA}$ greater than that required to elicit a calcium spike; the membrane potential was maintained at $-60 \mathrm{mV}$ by current injection. Tail potentials were measured by (1) recording their amplitude $250 \mathrm{~ms}$ after the peak and (2) integrating their area for $1 \mathrm{~s}$ beginning at the inflection point after the plateau. BayK8644 and nifedipine (Sigma-RBI, St. Louis, MO) were dissolved in DMSO and diluted (1:1000) immediately before use.

While recognizing that the calcium spike is a more indirect measure of somatic calcium conductance compared with voltage-clamped wholecell currents, we were concerned about the space-clamp limitations of these cells, given the rich dendritic expression of L-type channels (Hell et al., 1993). Unclamped calcium currents flowing through dendrites could easily distort a quantitative estimate of calcium channel activity. We chose to examine the calcium spike to avoid this problem but, more importantly, to allow a more direct comparison of our data with previous studies in which the alterations in the calcium spike had been linked to aging and cognitive performance (Pitler and Landfield, 1990; Moyer and Disterhoft, 1994).

Membrane potential measurements were not corrected for the liquid junction potential $(\sim 10 \mathrm{mV})$. Recordings were performed blind to the behavioral performance but not to the age of the animals. Waveform acquisition and analysis was performed with PClamp 8.0 (Axon Instruments). For sAHP and calcium spike-behavior correlation analysis, the sAHP amplitude for each animal is represented by the average value from all cells examined ( $n=3-9$ per rat). All statistical group comparisons, including those for behavioral data, were made with a one-way ANOVA, followed by a Tukey-Kramer post hoc test, which corrects for the effect of multiple comparisons. Data are presented as mean \pm SEM.

\section{Results}

Water maze impairments are observed in a subset of aged rats Aged rats in two separate cohorts were characterized as either AI or AU based on their mean escape latency calculated from training days 3-5 in the Morris water maze (see Materials and Methods). As reported in our previous study (Tombaugh et al., 2002), aged animals showed significantly longer and more variable swim distances during training, with a greatly increased variance, compared with young controls. Overall, aged rats used for electrophysiological studies swam slightly slower than young controls $(\mathrm{Y}, 27.2 \pm 0.1 \mathrm{~cm} / \mathrm{s} ; \mathrm{AU}, 24.8 \pm 0.1 \mathrm{~cm} / \mathrm{s} ; \mathrm{AI}, 24.3 \pm 0.1 \mathrm{~cm} / \mathrm{s})$. Importantly, there was no significant difference in swim speed be- 


\section{A: Acquisition}

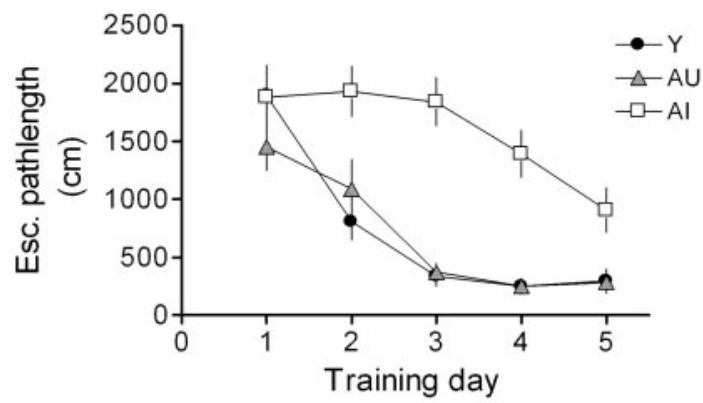

\section{B: Probes}
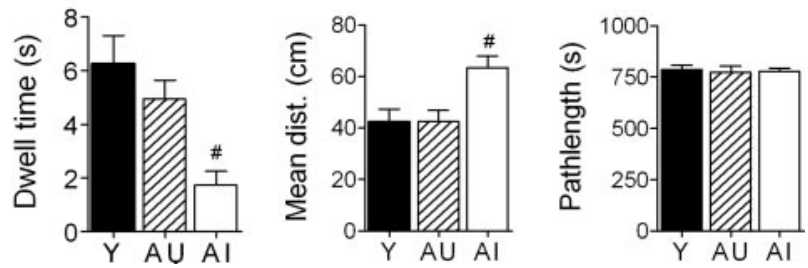

Figure 1. A subset of aged rats exhibits impaired performance in the Morris water maze. $\boldsymbol{A}$ Learning curves in the Morris water maze illustrating the performance of young and the AU and Al subgroups of aged rats as a function of path length to reach the hidden platform $(Y, n=9$; $\mathrm{AU}, n=8 ; \mathrm{Al}, n=10)$. Esc., Escape. $B$, Probe scores for each group were assessed on the fifth day of training. ${ }^{\#} p<0.05$ compared with the AU group.

tween AU and AI animals. Escape latencies and swim distances during training were highly correlated within each cohort $\left(r^{2}>0.95\right)$.

The acquisition curves for aged rats (cohort used for AHP recordings) illustrate the dramatic impairment in the ability of the AI subgroup to find the hidden platform (Fig. 1A).

During the probe trial, AI rats spent significantly less time in the annulus- 40 and maintained a greater mean distance from the platform location than either Y or AU rats (Fig. $1 B$ ). The path length swum during the probe trial was virtually identical among the three groups. When the platform was made visible, all animals used in this study achieved criterion escape performance. The average latency across the four trials for each group were as follows: Y, $6.7 \pm 0.4 \mathrm{~s} ; \mathrm{AU}, 8.0 \pm 0.8 \mathrm{~s} ; \mathrm{AI}, 8.2 \pm 0.7 \mathrm{~s}$ ). These results indicate that the altered ability of the AI animals to find the hidden platform was not attributable to a visual, motor, or motivational deficit.

The sAHP amplitude is larger in learning-impaired aged rats AHPs were reliably evoked from all cells in which stable recordings were made. These waveforms typically consisted of a sharp peak (mAHP) closely followed by a more slowly activating and decaying tail (sAHP). Compared with young rats, the peak of the sAHP was significantly larger in cells from AI rats when evoked from either resting potential or $-50 \mathrm{mV}$ (Fig. $2 \mathrm{~A}$ ). Additional recordings from young slices ( $n=12$ cells, 3 rats) prepared in sucrose-artificial CSF (ACSF) revealed no significant effect of the slicing conditions on sAHP amplitude ( $3.0 \pm 0.2$ vs $3.3 \pm 0.2 \mathrm{mV}$ in normal ACSF; $V_{\mathrm{h}}=-50 \mathrm{mV}$ ). To determine whether the age difference may have arisen from slight differences in firing frequency and the resulting integrated $\left[\mathrm{Ca}^{2+}\right]_{\mathrm{i}}$ signal, the sAHP was also evoked by a pattern of four spikes with fixed $15 \mathrm{~ms}$ intervals using 2 ms current pulses. Overall, sAHP amplitudes in the latter
A

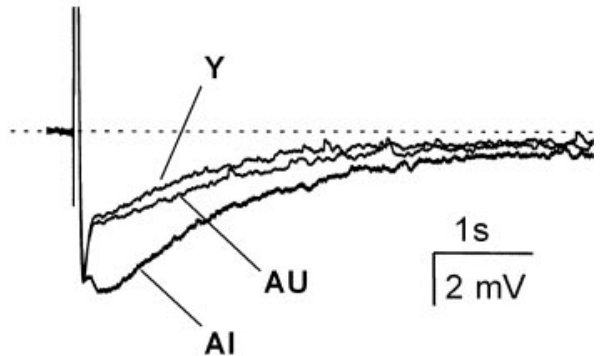

B
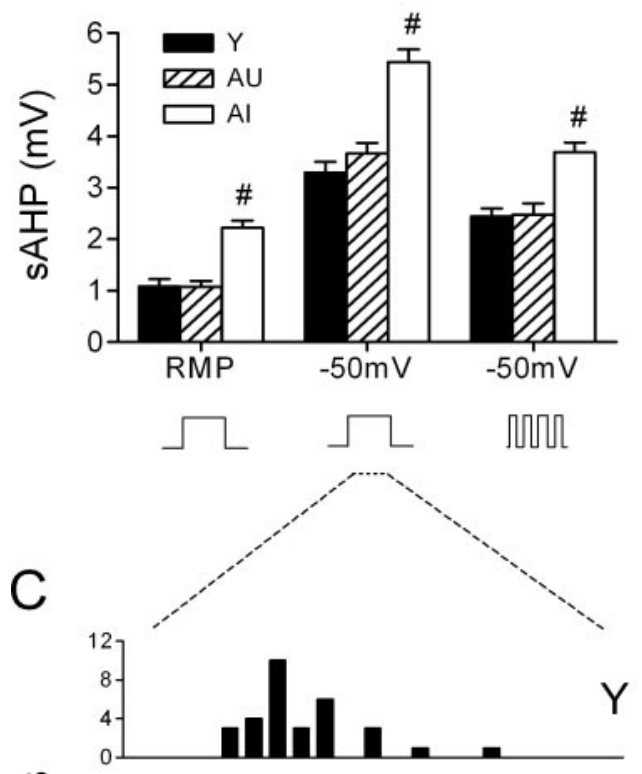

里

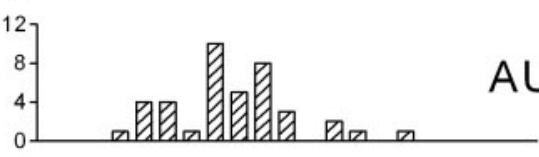

\#

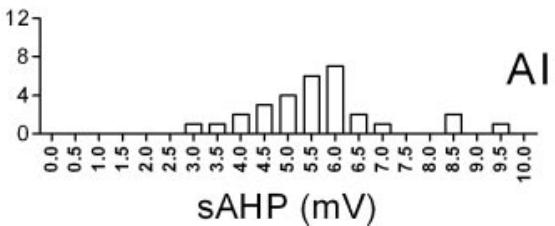

Figure 2. The SAHP is enlarged in CA1 neurons of Al rats. $\boldsymbol{A}$, Representative waveforms (average, $n=5$ sweeps) taken from a young $(\mathrm{Y})$, an AU, and an Al rat. In each case, the sAHP was evoked with a $50 \mathrm{~ms}$ current pulse sufficient to trigger four action potentials. The $V_{\mathrm{m}}$ was held at $-50 \mathrm{mV}$ by tonic current injection. $\boldsymbol{B}$, Summary of sAHP amplitudes from all cells recorded from either resting or depolarized potentials using a constant or pulsed current injection protocol to elicit action potentials. ${ }^{\#} p<0.001$ compared with the AU or young groups ( $Y$, $n=32 ; \mathrm{AU}, n=40 ; \mathrm{Al}, n=30)$. C, Distribution of sAHP amplitudes from all cells examined recorded from $50 \mathrm{mV}$ using a $50 \mathrm{~ms}$ square wave current pulse to elicit action potentials.

case were smaller, but the differences between groups were preserved (Fig. 2B). Histograms of these data sets revealed significant overlap in the distribution of sAHP amplitudes, as illustrated by the data derived from the single pulse protocol at $-50 \mathrm{mV}$ (Fig. 2C). In principle, the AU-AI differences in the mean delay interval between behavioral testing and slice preparation (2 vs 4 weeks) could have influenced the relative AU-AI difference in the sAHP, as suggested by a previous study in rabbits (Moyer et al., 1996). However, reanalysis of those AU and AI animals $(n=4$ 
each) with comparable delay intervals (AU, $22 \pm 5 \mathrm{~d}$; AI, $20 \pm 2 \mathrm{~d}$ ) showed that the sAHP amplitudes $\left(V_{\mathrm{h}}=-50 \mathrm{mV}\right)$ increased in each group by only $6-9 \%$, and their relative level of statistical significance to each other and to young controls was unchanged (data not shown).

The mean sAHP amplitude calculated from all cells in each aged subject was correlated with both acquisition and probe performance in the water maze (Fig. 3). Regression analysis among aged subjects showed that the sAHP amplitude (measured at the RMP) was related significantly to the escape path length $\left(r^{2}=0.56 ; p<0.01\right)$ during training, as well as to two probe measures: dwell time in the annulus-40 $\left(r^{2}=0.33 ; p<\right.$ $0.02)$ and mean distance to the platform $\left(r^{2}=0.24 ; p<0.05\right)$. These correlations were derived from animals representing the two behavioral extremes of the performance distribution.

\section{Spike accommodation is more pronounced in learning- impaired aged rats}

Membrane properties in young and aged CA1 neurons, including RMP, spike threshold, half-width, and amplitude, were nearly identical (Table 1). Cells from AI rats exhibited a slightly higher input resistance $\left(R_{\text {in }}\right)$ compared with Y rats, although this measure did not differ significantly for AI-AU or AU-Y comparisons. During prolonged depolarization, all cells displayed spikefrequency adaptation, but the degree of accommodation was significantly more pronounced in AI rats compared with either AU or young controls (Fig. 4A). This difference first reached statistical significance during a current pulse of $300 \mathrm{pA}$, which typically evoked eight spikes in young rats, seven in AU rats, and five in AI rats (Fig. $4 B$ ). In contrast, the instantaneous firing frequency during a $350 \mathrm{pA}$ current pulse, as judged by the intervals of the first five spikes, did not differ among the three groups (Fig. 4C). As is seen often, spikes became progressively broader in all groups during sustained firing. The degree of spike broadening, as assessed by the half-width ratio of the fourth to the first spike, did not differ significantly among the three groups $(\mathrm{Y}, 1.55 \pm 0.03$; AU, $1.61 \pm 0.05 ; \mathrm{AI}, 1.61 \pm 0.05)$.

\section{cAMP $_{\mathrm{i}}$ suppresses both the SAHP and accomodation in young and aged rats}

In a separate series of recordings, the cAMP analog 8-CPT-cAMP $(50 \mu \mathrm{M})$ was applied intracellularly via the patch pipette to suppress the sAHP (Fig. 5A). Our goal was to gain a more accurate measurement of the $\mathrm{MAHP}$, which typically overlapped the sAHP.

Cells dialyzed with 8-CPT-cAMP had a small or undetectable sAHP but consistently expressed a prominent mAHP, which could be partially blocked with apamin ( $200 \mathrm{~nm}$; data not shown). In these experiments, we found no group differences in $\mathrm{mAHP}$ amplitude, either at the resting potential or when cells were depolarized to $-50 \mathrm{mV}$ (Fig. 5B). No measurable sAHP remained at the RMP, although a small sAHP could be evoked from $-50 \mathrm{mV}$ (Fig. 5C), which was nearly identical in size among the three groups (compare with Fig. 2 B). Dialysis with 8-CPT-cAMP both enhanced cell excitability and abolished the learning-related difference in accommodation described above (Fig. $5 D, E$; compare with Fig. $4 A, B)$. Under these conditions, we observed no group differences in action potential properties (data not shown) or in
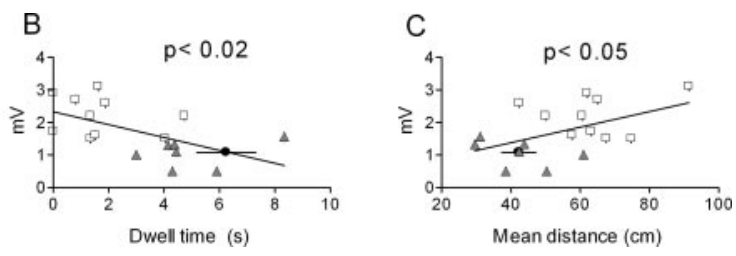

Figure 3. SAHP amplitude covaries with water maze performance among aged rats. Linear regression analysis of sAHP ampli(2) mean escape (Esc.) path length (days 3-5) during training $(\boldsymbol{A})$ as well as two $(\boldsymbol{B}, \boldsymbol{C})$ that were used as an index of the subjects' reliance on a spatial strategy in the maze. Each data point reflects the mean sAHP amplitude of all cells $(n=3-9)$ examined from that animal. The data point in each panel depicting the mean performance for young rats was not included in the regression analysis.

instantaneous firing frequency, which was no different from control recordings (Fig. 5F; compare with Fig. 4C).

\section{Calcium spikes are enhanced in aged rats}

A separate set of behaviorally characterized rats was used to evaluate the relationship of the calcium spike in CA1 neurons to water maze performance. These rats exhibited escape latencies and probe performance measures similar to those for the rats in which the SAHP was recorded (data not shown). Calcium spikes were readily evoked from CA1 neurons by using a $\mathrm{Cs}^{+}$-based intracellular solution in the presence of TTX. After its peak, the calcium spike displayed a distinct plateau phase, followed by a slowly decaying tail (Fig. 6A), as reported by others (Pitler and Landfield, 1990; Moyer and Disterhoft, 1994). Exposure to low$\mathrm{Ca}^{2+}(0.1 \mathrm{~mm})$ ACSF rapidly abolished these spikes (data not shown). Previous work has shown that in CA1 neurons, L-type calcium channels contribute to the calcium spike (Moyer and Disterhoft, 1994; Campbell et al., 1996) and are functionally linked to channels that underlie the sAHP (Moyer et al., 1992; Disterhoft et al., 1996; Marrion and Tavalin, 1998; Bowden et al., 2001). In young rats, bath application of the selective L-type channel agonist $(-)$ BayK8466 (1 $\mu \mathrm{M})$ enhanced the integrated tail potential of the calcium spike and broadened its peak, mimicking the profile of the calcium spike seen in cells from AI rats (Fig. $6 B, C)$. Nifedipine $(5 \mu \mathrm{M})$ had the opposite effect $(n=5$; data not shown). In young rats, ( - BayK8644 also enlarged the sAHP (Fig. 6D) and enhanced the degree of accommodation ( $n=2$; data not shown).

On average, calcium spikes from AI rats were larger than those seen in young or AU rats. Peak width was slightly larger in AI rats (Fig. 7A), as was the tail amplitude (Fig. 7B) (see Materials and Methods), whereas peak and plateau amplitudes were not different. The mean AI-AU difference in the integrated tail potential also reached statistical significance $(p<0.05$; Tukey-Kramer post hoc test), whereas the data distributions overlapped to a degree (Fig. 7C) comparable with that of the sAHP. The calcium spike tail amplitude, but not its integrated area, correlated significantly $\left(r^{2}=0.61 ; p<0.001\right)$ (Fig. $8 A$, solid line) with the escape path length (day $3-5$ average) in the water maze among aged rats. However, the AI and AU data sets were both tightly clustered, yielding a small $p$ value that reflected the mean group difference rather than a clear gradient of performance among individual rats. Thibault and Landfield (1996) have reported a significant correlation between calcium channel density and escape latency in the water maze using Spearman's rank analysis. Using the same analysis, we found escape latency among aged rats to be significantly related to both tail amplitude (Fig. $8 \mathrm{~A}$ ) and integrated tail area $(r=0.51 ; p<0.05)$. In contrast, neither calcium spike measure correlated significantly with either of the same two probe measures that covaried significantly with the sAHP (Fig. 


\begin{tabular}{llllll}
\hline \multirow{2}{*}{ Group } & & & \multicolumn{3}{c}{ Spike properties } \\
\cline { 4 - 6 } & $V_{\mathrm{m}}(\mathrm{mV})$ & $R_{\text {in }}(\mathrm{M} \Omega)$ & Threshold $(\mathrm{MV})$ & Half-width $(\mathrm{mV})$ & Amplitude $(\mathrm{mV})$ \\
\hline Young $(n=32)$ & $-61.6 \pm 0.4$ & $88 \pm 3$ & $-40.2 \pm 0.5$ & $1.02 \pm 0.02$ & $78 \pm 1$ \\
$\mathrm{AU}(n=48)$ & $-61.4 \pm 0.3$ & $99 \pm 4$ & $-40.0 \pm 0.4$ & $1.02 \pm 0.02$ & $76 \pm 1$ \\
$\mathrm{Al}(n=30)$ & $-61.1 \pm 0.4$ & $109 \pm 4^{*}$ & $-41.2 \pm 0.4$ & $1.02 \pm 0.01$ & $77 \pm 1$ \\
\hline
\end{tabular}

The number of neurons examined (in parentheses) was derived from nine rats for each group. ${ }^{*} p<0.001$ compared with young rats (ANOVA with Tukey-Kramer post hoc test).
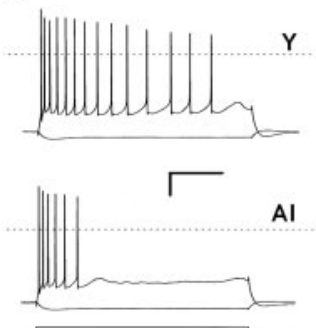

B

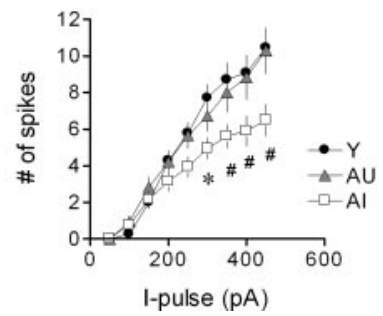

C

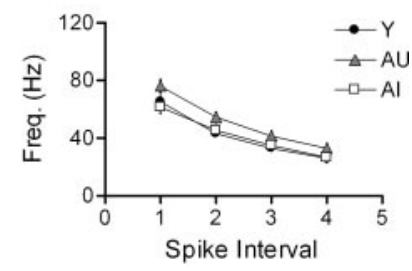

Figure 4. CA1 neurons from Al rats exhibit depressed excitability. $\boldsymbol{A}$, Representative recordings from young $(\mathrm{Y})$ and $\mathrm{AI} C \mathrm{C} 1$ neurons during tonic current injection ( $-100,+450 \mathrm{pA} ; 800 \mathrm{~ms}$ ). The dashed line represents $0 \mathrm{mV}$. Calibration: $20 \mathrm{mV}, 0.2 \mathrm{~s} . \boldsymbol{B}$, Summary of all cells illustrated in $\boldsymbol{A}(\mathrm{Y}, n=18 ; \mathrm{AU}, n=14 ; \mathrm{Al}, n=17)$. $\boldsymbol{C}$, Instantaneous firing frequency of the first four interspike intervals from the same group of cells. ${ }^{*} p<0.05$; ${ }^{*} p<0.01$ compared with AU group; two-factor repeated-measures ANOVA followed by Tukey-Kramer post hoc test. I-pulse, Current pulse.
Table 1. Membrane properties of CA1 neurons from young and aged rats

man's correlation $(p>0.05$; data not shown). This negative finding was not attributable to gross differences in the two cohorts, because the young, $\mathrm{AU}$, and $\mathrm{AI}$ rats in each cohort exhibited similar relative acquisition and probe trail performance (data not shown).

\section{Discussion}

The principal finding in this study is that the sAHP recorded from CA1 neurons is selectively enhanced in aged rats that had shown spatial learning deficits in the Morris water maze. The increase in sAHP amplitude was also tightly coupled with depressed cell excitability and associated with a larger calcium spike. The strong correlation between water maze performance and the sAHP among aged rats extends the original finding in rabbits to a second species, providing compelling support for its role in shaping hippocampaldependent cognition.

A role for the sAHP has been highlighted in previous studies of young streptozotocin-treated rats that exhibit
A
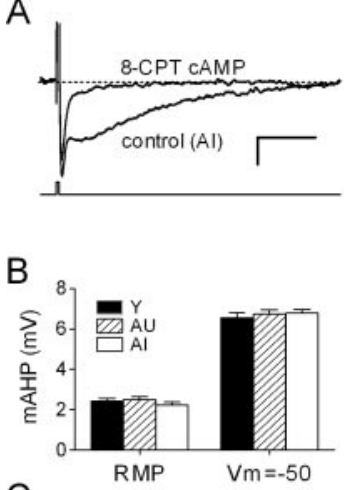

C

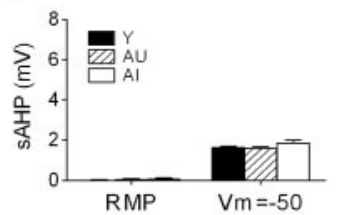

D

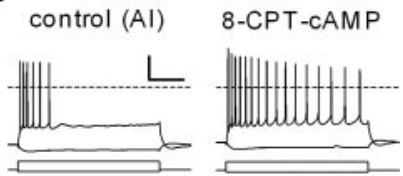

E

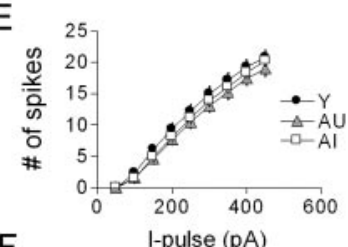

F

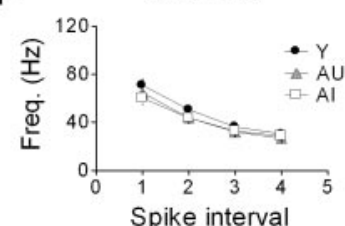

Figure 5. Suppression of the SAHP reveals no age-related difference in the mAHP. A, Intracellular dialysis of CA1 neurons with $50 \mu \mathrm{m}$ 8-CPT-CAMP virtually abolished the SAHP while preserving the mAHP. Representative waveforms ( $n=5$ sweeps) were acquired with or without cAMP from two cells in the same slice of an Al rat $\left(V_{\mathrm{m}}=-50 \mathrm{mV}\right)$. Calibration: $2 \mathrm{mV}, 1 \mathrm{~s} . \boldsymbol{B}$, mAHP amplitude, measured either at resting (RMP) or at $V_{\mathrm{h}}=-50 \mathrm{mV}$, is not affected by aging: $Y, n=18$ neurons, 3 rats; $A U, n=18$ neurons, 4 rats; Al, $n=14$ neurons, 3 rats. $C$, After dialysis with 8-CPT-CAMP, a residual SAHP can be detected at depolarized potentials. D, Prolonged ( $800 \mathrm{~ms})$ current injection $(-100,+450 \mathrm{pA})$ in the same two cells shown in $A$ illustrates the dramatic effect of the CAMP analog on accommodation. $\boldsymbol{E}$, Summary of cell firing from experiments as shown in $\boldsymbol{D}$, in which all cells were dialyzed with 8-CPT-CAMP. $\boldsymbol{F}$, Instantaneous firing frequency (Freq.) of the first four interspike intervals from the same set of neurons as in $\boldsymbol{E}$. I-pulse, Current pulse.

$8 B$ ). Including the young animals in the calcium spike correlation analyses (Fig. 8, dashed line) did not change this result. When plotted against either set of ranked probe scores, the calcium spike measures also failed to generate a significant Spear- both impaired performance in the Morris water maze and a larger sAHP (Kamal et al., 2000, 2003). Another study in normal young rats has also identified an inverse relationship between the sAHP and water maze learning ability (Oh et al., 2003). In contrast to our study, neither of these previous studies included aged animals, and correlations of individual maze performance with the sAHP were not examined. However, these studies collectively underscore a general link between the sAHP in CA1 neurons and spatial learning ability.

In our hands, aged rats exhibited a range of water maze performance during training and were defined statistically as either $\mathrm{AI}$ or AU, as described in our previous study (Tombaugh et al., 2002). The fact that both young and AU animals performed comparably in both the acquisition and probes trials suggests that the animals in each group were equally certain of the platform location and solved the task using a spatial strategy (Tombaugh et al., 2002). Therefore, comparisons made between the AI and AU groups are more likely to reveal changes that may be linked to cognitive decline by eliminating aging as a variable.

The process of learning itself has been reported to blunt the sAHP in both rabbits and rats (Moyer et al., 1996, 2000; Oh et al., 2003). We regard this effect as an event-driven process that is likely to be fundamentally different from the age-driven change in the sAHP we describe. We did not directly examine this training effect, which appears to reverse within $7 \mathrm{~d}$ in rabbits after eye-blink conditioning. Whether this time course is similar in rats, and whether it occurs in aged subjects, is not known.

In addition to having a larger SAHP, neurons from AI rats also showed more robust spike accommodation with no shift in instantaneous firing frequency. This observation is consistent with data showing that the sAHP specifically regulates accommodation in these and other cell types, whereas initial firing frequency is more strongly regulated by the apamin-sensitive mAHP (Lancaster and Nicoll, 1987; Pedarzani et al., 2001; Faber and Sah, 2002). When the mAHP was isolated by intracellular dialysis with 8-CPT-cAMP, we found no group differences in its amplitude, as would be predicted from the lack of change in the instantaneous 
firing rate. As expected, 8-CPT-cAMP enhanced cell excitability in all groups, also abolishing the AU-AI difference in spike accommodation. Thus, the spatial learning ability of aged rats appears more tightly linked to the sAHP than the mAHP. Of note, a recent study in young rats has reported changes in both components (Oh et al., 2003).

Basal protein kinase A (PKA) activity has been suggested to provide a tonic constraint on the size of the sAHP in CA1 neurons (Pedarzani et al., 1998). This relationship is inverse in that lower PKA activity results in a lager sAHP. Both basal and stimulated levels of hippocampal PKA activity have been found to decline dramatically in senescent ( $>24$ months of age) rats (Karege et al., 2001a,b), arguably because of reduced PKA enzyme expression rather than to increased cAMP degradation (Tohda et al., 1996; Karege et al., 2001a; Davare and Hell, 2003). However, others have concluded that impaired PKA signaling in the aging hippocampus is attributable to reduced adenylyl cyclase activity (Araki et al., 1996, 1997; Ramos et al., 2003).

Either reduced PKA levels or cyclase activity could, in principle, explain the sAHP increase we observed in $\mathrm{AI}$ rats. If PKA enzyme levels were reduced in AI rats, elevation of cAMP to levels that maximally activated PKA would likely preserve the relative AU-AI difference in the SAHP, provided that PKA activity remained below the level capable of fully inhibiting the sAHP channels (i.e., floor effect). However, if the larger sAHP arose from reduced basal cAMP levels, elevating cAMP artificially would likely obscure the AU-AI sAHP difference. Our results support the second scenario. Intracellular dialysis of a $50 \mu \mathrm{M} 8$ 8-CPT-cAMP reduced the SAHP to comparable levels in all groups $\left(V_{\mathrm{h}}=-50\right.$ $\mathrm{mV}$ ) and also normalized the AU-AI difference in accommodation. Thus, a reduced capacity to synthesize cAMP, previously linked to contextual learning deficits in rats and mice (Wu et al., 1995; Mons et al., 2004; Wang et al., 2004), may contribute to the age-related sAHP increase we describe.

A second objective of our study was to test the putative linkage between calcium influx and cognitive impairment by asking whether the linkage we observed between the sAHP and water maze learning was preserved for the calcium spike. Consistent with previous studies (Pitler and Landfield, 1990; Moyer and Disterhoft, 1994), we found that the tail potentials of the calcium spike are larger in aged rats, specifically in the AI group. This result, along with the mimicking effects of (-)BayK8644, supports the general view that excessive $\mathrm{Ca}^{2+}$ influx via L-type channels is detrimental to hippocampal function during aging (Thibault et al., 2001). Moreover, the Spearman's rank analysis for our calcium spike and escape latency data closely matches the correlation reported previously between the L-type calcium
C

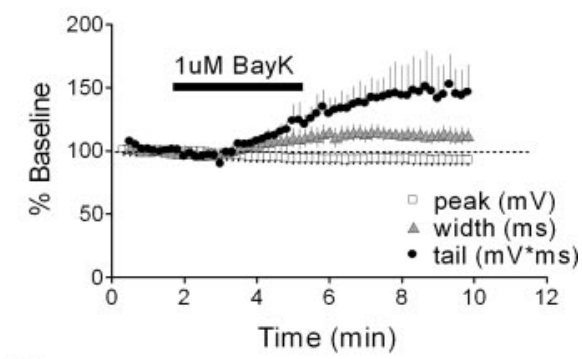

D

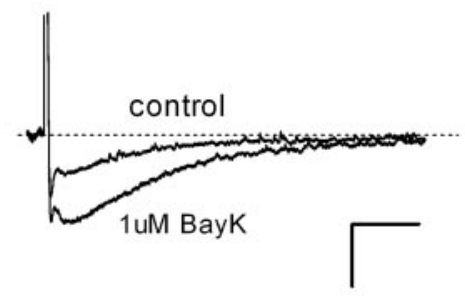

Figure 6. The calcium spike in CA1 neurons is driven essentially by L-type channels. $A$, Representative calcium spike (young rat) ustrating where measurements were taken. B, Bath application of (-)BayK8644 (BayK; $1 \mu \mathrm{M}$ ) increases peak width and tail of Summary of experiments depicted in $\boldsymbol{B}(n=4$ neurons). $\boldsymbol{D}$, Bath application of $(-)$ BayK8644 $(1 \mu \mathrm{M})$ amplifies the sAHP. Example

A

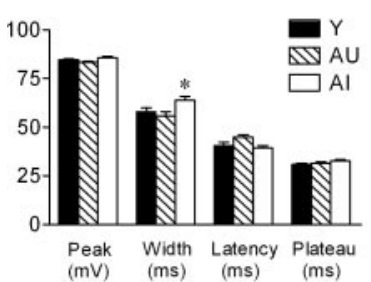

Figure 7. The calcium spike is enhanced in CA1 neurons of Al rats. $A$, Calcium spike width, but not its peak or plateau amplitude, is larger in Al rats. ${ }^{*} p<0.05$ compared with AU rats. $B$, Calcium spike tail amplitude is $\sim 40 \%$ larger compared with young or AU distribution (compare with Fig. 20); the Al group mean is statistically different from the $\mathrm{AU}(p<0.05)$ and $\mathrm{Y}(p<0.01)$ groups. The sample sizes are as follows: $\mathrm{Y}, n=31$ neurons, 9 rats; $\mathrm{AU}, n=49$ neurons, 11 rats; $\mathrm{Al}, n=40$ neurons, 8 rats. channel density and escape latency in aged rats (Thibault and Landfield, 1996).

However, in contrast to the sAHP, calcium spike measures failed to correlate significantly with the same behavioral probe scores that correlated with the sAHP. These correlations were derived from restricted subsets of aged animals, and so it remains possible that the correlation might have been stronger if we had included rats with intermediate probe scores. However, given the overlapping probe scores for the $\mathrm{AU}$ and $\mathrm{AI}$ rats, it is not clear that including rats with intermediate probe scores in this case would have had much effect. To the extent that probe measures can reveal dependence on a spatial (i.e., hippocampal-dependent) strategy, this result was contrary to our expectations based on the functional coupling between hippocampal L-type calcium channels and the sAHP (Marrion and Tavalin, 1998; Bowden et al., 2001). This discrepancy may reflect the role of L-type channels in nonhippocampal brain areas, such as the striatum, known to govern procedural elements of water maze acquisition but that do 


\section{A: Acquisition}
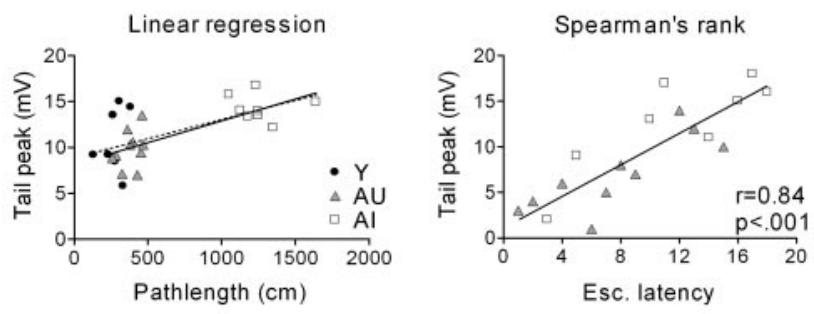

\section{B: Probe}
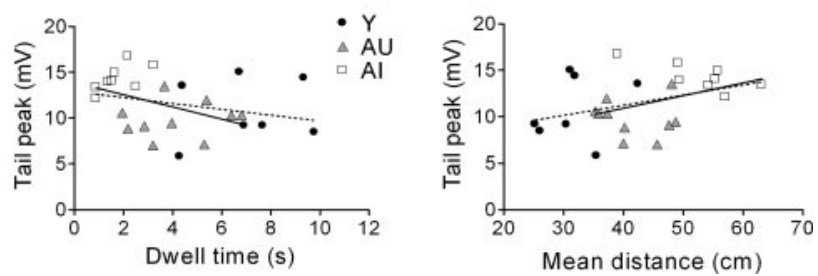

Figure 8. The calcium spike correlates with water maze acquisition but not probe performance. $\boldsymbol{A}$, Linear regression and Spearman's rank plots of the relationship between calcium spike tail amplitude ( $p<0.01$ ) and days 3-5 mean escape path length or latency in the water maze. $\boldsymbol{B}$, Linear regression plots of calcium spike tail amplitude and two probe measures: dwell time in the target zone and mean distance to platform location, both of which failed to reach significance $(p>0.05)$. The solid line depicts regression for aged rats only; the dashed line reflects analysis of both young and aged subjects. Each data point reflects the mean tail amplitude of all cells examined from that animal $(n=3-7)$.

not underlie place learning (Packard and McGaugh, 1996; Devan et al., 1999; Okita et al., 2000).

From these findings, we conclude that an increase in CA1 $\mathrm{Ca}^{2+}$ influx, as reported by the calcium spike, reflects an aging phenomenon that may contribute to, but is not solely responsible for, the process of cognitive decline. In this regard, it is notable that hippocampal L-type calcium channel activity can be enhanced by PKA-dependent phosphorylation (Gray and Johnston, 1987; Hell et al., 1995), which increases during aging (Davare and Hell, 2003). Given the established action of PKA to suppress the sAHP, these findings are difficult to reconcile with the idea that an age-related sAHP increase arises exclusively from enhanced calcium channel activity.

Calcium spikes presumably arise from the opening of many L-type calcium channel subtypes, with the largest contribution ( $\sim 80 \%$ ) from L-type channels containing the $\alpha 1 \mathrm{C}$ subunit (Hell et al., 1993). It remains possible that a minor L-type calcium channel subtype is coupled with the sAHP channel in CA1 neurons, yet contributes little to the calcium spike (Hell et al., 1994). Channels containing the $\alpha 1 \mathrm{D}$ subunit have been linked to the sAHP in CA1 neurons (Bowden et al., 2001), and the expression level of the 1D subunit has been reported to increase in the aging rat brain (Veng and Browning, 2002), although unambiguous quantitative measures of functional $\alpha 1 \mathrm{D}$ channels in aged CA1 neurons are lacking.

Overall, the present study portrays the sAHP in CA1 neurons as a key factor in shaping spatial learning ability across species and behavioral tasks. Precisely why the sAHP increases with age is not known. Our findings strengthen the inverse relationship between calcium influx, sAHP amplitude, and water maze acquisition, but they de-emphasize enhanced $\mathrm{Ca}^{2+}$ influx as the sole molecular determinant of both the increased sAHP and the associated decline in spatial learning during aging. Our results also depict depressed cAMP signaling as one important factor that may drive the age-associated sAHP increase. Other possibilities certainly exist, including a change in the number or conductance of sAHP channels themselves.

Elevated phosphatase activity, lower PKC activity, or reduced muscarinic receptor activity also may be involved (Pedarzani et al.,1998; Krause and Pedarzani, 2000; Weiss et al., 2000), because each of these has been linked to impaired water maze performance in aged rats (Colombo et al., 1997; Foster et al., 2001; Dickinson-Anson et al., 2003). Identification of the sAHP channel will undoubtedly help resolve this question, and we hope that our findings provide new incentive for its discovery.

\section{References}

Araki T, Kato H, Shuto K, Fujiwara T, Itoyama Y (1996) Effect of nitric oxide synthase inhibitor on age-related changes in second messenger systems and calcium channels in rats. Metab Brain Dis 12:83-92.

Araki T, Kato H, Shuto K, Itoyama Y (1997) Age-related changes in $\left[{ }^{3} \mathrm{H}\right]$ nimodipine and $\left[{ }^{3} \mathrm{H}\right]$ rolipram binding in the rat brain. J Pharm Pharmacol 49:310-314.

Azouz R, Jensen MS, Yaari Y (1996) Ionic basis of spike after-depolarization and burst generation in adult rat hippocampal CAl pyramidal cells. J Physiol (Lond) 492:211-223.

Backman C, Rose GM, Hoffer BJ, Henry MA, Bartus RT, Friden P, Granholm AC (1996) Systemic administration of a nerve growth factor conjugate reverses age-related cognitive dysfunction and prevents cholinergic neuron atrophy. J Neurosci 16:5437-5442.

Barnes CA, McNaughton BL (1985) An age comparison of the rates of acquisition and forgetting of spatial information in relation to long-term enhancement of hippocampal synapses. Behav Neurosci 99:1040-1048.

Bowden SE, Fletcher S, Loane DJ, Marrion NV (2001) Somatic colocalization of rat SK1 and D class [Ca(v) 1.2] L-type calcium channels in rat CA1 hippocampal pyramidal neurons. J Neurosci 21:RC175(1-6).

Campbell LW, Hao SY, Thibault O, Blalock EM, Landfield PW (1996) Aging changes in voltage-gated calcium currents in hippocampal CA1 neurons. J Neurosci 16:6286-6295.

Clayton DA, Browning MD (2001) Deficits in the expression of the NR2B subunit in the hippocampus of aged Fisher 344 rats. Neurobiol Aging 22:165-168.

Colombo PJ, Wetsel WC, Gallagher M (1997) Spatial memory is related to hippocampal subcellular concentrations of calcium-dependent protein kinase C isoforms in young and aged rats. Proc Natl Acad Sci USA 94:14195-14199.

Davare MA, Hell JW (2003) Increased phosphorylation of the neuronal L-type $\mathrm{Ca}^{2+}$ channel Cav1.2 during aging. Proc Natl Acad Sci USA 100:16018-16023.

Deupree DL, Turner DA, Watters CL (1991) Spatial performance correlates with in vitro potentiation in young and aged Fischer 344 rats. Brain Res 554:1-9.

Devan BD, McDonald RJ, White NM (1999) Effects of medial and lateral caudate-putamen lesions on place- and cue-guided behaviors in the water maze: relation to thigmotaxis. Behav Brain Res 100:5-14.

Dickinson-Anson H, Winkler J, Fisher LJ, Song HJ, Poo M, Gage FH (2003) Acetylcholine-secreting cells improve age-induced memory deficits. Mol Ther 8:51-61.

Disterhoft JF, Thompson LT, Moyer Jr JR, Mogul DJ (1996) Calciumdependent afterhyperpolarization and learning in young and aging hippocampus. Life Sci 59:413-420.

Eckles-Smith K, Clayton D, Bickford P, Browning MD (2000) Caloric restriction prevents age-related deficits in LTP and in NMDA receptor expression. Mol Brain Res 78:154-162.

Faber ES, Sah P (2002) Physiological role of calcium-activated potassium currents in the rat lateral amygdala. J Neurosci 22:1618-1628.

Foster TC, Sharrow KM, Masse JR, Norris CM, Kumar A (2001) Calcineurin links $\mathrm{Ca}^{2+}$ dysregulation with brain aging. J Neurosci 21:4066-4073.

Gage FH, Dunnett SB, Björklund A (1984) Spatial learning and motor deficits in aged rats. Neurobiol Aging 5:43-48.

Geinisman Y, Ganeshina O, Yoshida R, Berry RW, Disterhoft JF, Gallagher M (2004) Aging, spatial learning, and total synapse number in the rat CA1 stratum radiatum. Neurobiol Aging 25:407-416.

Giese KP, Peters M, Vernon J (2001) Modulation of excitability as a learning and memory mechanism: a molecular genetic perspective. Physiol Behav 73:803-810.

Gray R, Johnston D (1987) Noradrenaline and beta-adrenoceptor agonists 
increase activity of voltage-dependent calcium channels in hippocampal neurons. Nature 327:620-622.

Hell J, Westenbroek R, Warner C, Ahlijanian M, Prystay W, Gilbert M, Snutch T, Catterall W (1993) Identification and differential subcellular localization of the neuronal class C and class D L-type calcium channel alpha 1 subunits. J Cell Biol 123:949-962.

Hell JW, Westenbroek RE, Elliott EM, Catterall WA (1994) Differential phosphorylation, localization, and function of distinct alpha 1 subunits of neuronal calcium channels. Two size forms for class B, C, and D alpha 1 subunits with different COOH-termini. Ann NY Acad Sci 747:282-293.

Hell JW, Yokoyama CT, Breeze LJ, Chavkin C, Catterall WA (1995) Phosphorylation of presynaptic and postsynaptic calcium channels by cAMPdependent protein kinase in hippocampal neurons. EMBO J 14:3036-3044.

Holland PC, Bouton ME (1999) Hippocampus and context in classical conditioning. Curr Opin Neurobiol 9:195-202.

Hollup SA, Kjelstrup KG, Hoff J, Moser MB, Moser EI (2001) Impaired recognition of the goal location during spatial navigation in rats with hippocampal lesions. J Neurosci 21:4505-4513.

Kamal A, Biessels GJ, Duis SE, Gispen WH (2000) Learning and hippocampal synaptic plasticity in streptozotocin-diabetic rats: interaction of diabetes and ageing. Diabetologia 43:500-506.

Kamal A, Artola A, Biessels GJ, Gispen WH, Ramakers GMJ (2003) Increased spike broadening and slow afterhyperpolarization in CA1 pyramidal cells of streptozotocin-induced diabetic rats. Neuroscience 118:577-583.

Karege F, Lambercy C, Schwald M, Steimer T, Cisse M (2001a) Differential changes of cAMP-dependent protein kinase activity and 3H-cAMP binding sites in rat hippocampus during maturation and aging. Neurosci Lett 315:89-92.

Karege F, Schwald M, Lambercy C, Murama JJ, Cisse M, Malafosse A (2001b) A non-radioactive assay for the cAMP-dependent protein kinase activity in rat brain homogenates and age-related changes in hippocampus and cortex. Brain Res 903:86-93.

Krause M, Pedarzani P (2000) A protein phosphatase is involved in the cholinergic suppression of the $\mathrm{Ca}^{2+}$-activated $\mathrm{K}^{+}$current sI(AHP) in hippocampal pyramidal neurons. Neuropharmacology 39:1274-1283.

Lancaster B, Nicoll RA (1987) Properties of two calcium-activated hyperpolarizations in rat hippocampal neurones. J Physiol (Lond) 389:187-203.

Landfield PW (1996) Aging-related increase in hippocampal calcium channels. Life Sci 59:399-404

Landfield PW, Pitler TA (1984) Prolonged $\mathrm{Ca}^{2+}$-dependent afterhyperpolarizations in hippocampal neurons of aged rats. Science 226:1089-1092.

Marrion NV, Tavalin SJ (1998) Selective activation of $\mathrm{Ca}^{2+}$-activated $\mathrm{K}^{+}$ channels by co-localized $\mathrm{Ca}^{2+}$ channels in hippocampal neurons. Nature 395:900-905.

Mons N, Segu L, Nogues X, Buhot MC (2004) Effects of age and spatial learning on adenylyl cyclase mRNA expression in the mouse hippocampus. Neurobiol Aging 25:1095-1106.

Morris RGM, Garrud P, Rawlins JNP, O'Keefe J (1982) Place navigation is impaired in rats with hippocampal lesions. Nature 297:681-683.

Morris RGM, Schenk F, Tweedie F, Jarrard LE (1990) Ibotenate lesions of hippocampus and/or subiculum: dissociating components of allocentric spatial learning. Eur J Neurosci 2:1016-1028.

Moyer Jr JR, Brown TH (1998) Methods for whole-cell recording from visually preselected neurons of perirhinal cortex in brain slices from young and aging rats. J Neurosci Methods 86:35-54.

Moyer Jr JR, Disterhoft JF (1994) Nimodipine decreases calcium action potentials in rabbit hippocampal CA1 neurons in an age-dependent and concentration-dependent manner. Hippocampus 4:11-17.

Moyer Jr JR, Thompson LT, Black JP, Disterhoft JF (1992) Nimodipine increases excitability of rabbit CA1 pyramidal neurons in an age- and concentration-dependent manner. J Neurophysiol 68:2100-2109.

Moyer Jr JR, Thompson LT, Disterhoft JF (1996) Trace eyeblink conditioning increases CA1 excitability in a transient and learning-specific manner. J Neurosci 16:5536-5546.

Moyer JR, Power JM, Thompson LT, Disterhoft JF (2000) Increased excitability of aged rabbit CA1 neurons after trace eyeblink conditioning. J Neurosci 20:5476-5482.

Norris CM, Halpain S, Foster TC (1998a) Reversal of age-related alterations in synaptic plasticity by blockade of L-type $\mathrm{Ca}^{2+}$ channels. J Neurosci 18:3171-3179.

Norris CM, Halpain S, Foster TC (1998b) Alterations in the balance of protein kinase/phosphatase activities parallel reduced synaptic strength during aging. J Neurophysiol 80:1567-1570.
Oh MM, Kuo AG, Wu WW, Sametsky EA, Disterhoft JF (2003) Watermaze learning enhances excitability of CA1 pyramidal neurons. J Neurophysiol 90:2171-2179.

Okita M, Watanabe Y, Taya K, Utsumi H, Hayashi T (2000) Presynaptic L-type $\mathrm{Ca}^{2+}$ channels on excessive dopamine release from rat caudate putamen. Physiol Behav 68:641-649.

Otto T, Eichenbaum H, Wiener SI, Wible CG (1991) Learning-related patterns of CA1 spike trains parallel stimulation parameters optimal for inducing hippocampal long-term potentiation. Hippocampus 1:181-192.

Packard MG, McGaugh JL (1996) Inactivation of hippocampus or caudate nucleus with lidocaine differentially affects expression of place and response learning. Neurobiol Learn Mem 65:65-72.

Paulsen O, Sejnowski TJ (2000) Natural patterns of activity and long-term synaptic plasticity. Curr Opin Neurobiol 10:172-179.

Pedarzani P, Krause M, Haug T, Storm JF, Stuhmer W (1998) Modulation of the $\mathrm{Ca}^{2+}$-activated $\mathrm{K}^{+}$current sIAHP by a phosphatase-kinase balance under basal conditions in rat CA1 pyramidal neurons. J Neurophysiol 79:3252-3256.

Pedarzani P, Mosbacher J, Rivard A, Cingolani LA, Oliver D, Stocker M, Adelman JP, Fakler B (2001) Control of electrical activity in central neurons by modulating the gating of small conductance $\mathrm{Ca}^{2+}$-activated $\mathrm{K}^{+}$ channels. J Biol Chem 276:9762-9769.

Pike FG, Meredith RM, Olding AW, Paulsen O (1999) Rapid report: postsynaptic bursting is essential for "Hebbian" induction of associative long-term potentiation at excitatory synapses in rat hippocampus. J Physiol (Lond) 518:571-576.

Pitler TA, Landfield PW (1990) Aging-related prolongation of calcium spike duration in rat hippocampal slice neurons. Brain Res 508:1-6.

Power JM, Oh MM, Disterhoft JF (2001) Metrifonate decreases SI(AHP) in CA1 hippocampal neurons in vitro. J Neurophysiol 85:319-322.

Quirion R, Wilson A, Rowe W, Aubert I, Richard J, Doods H, Parent A, N. W., Meaney MJ (1995) Facilitation of acetylcholine release and cognitive performance by an $\mathrm{M}(2)$-muscarinic receptor antagonist in aged memory-impaired rats. J Neurosci 15:1455-1462.

Ramos BP, Birnbaum SG, Lindenmayer I, Newton SS, Duman RS, Arnsten AF (2003) Dysregulation of protein kinase a signaling in the aged prefrontal cortex: new strategy for treating age-related cognitive decline. Neuron 40:835-845.

Rapp PR, Gallagher M (1996) Preserved neuron number in the hippocampus of aged rats with spatial learning deficits. Proc Natl Acad Sci USA 93:9926-9930.

Rapp PR, Stack EC, Gallagher M (1999) Morphometric studies of the aged hippocampus: I. Volumetric analysis in behaviorally characterized rats. J Comp Neurol 403:459-470.

Smith TD, Adams MM, Gallagher M, Morrison JH, Rapp PR (2000) Circuitspecific alterations in hippocampal synaptophysin immunoreactivity predict spatial learning impairment in aged rats. J Neurosci 20:6587-6593.

Thibault O, Landfield PW (1996) Increase in single L-type calcium channels in hippocampal neurons during aging. Science 272:1017-1020.

Thibault O, Hadley R, Landfield PW (2001) Elevated postsynaptic $\left[\mathrm{Ca}^{2+}\right]_{\mathrm{i}}$ and L-type calcium channel activity in aged hippocampal neurons: relationship to impaired synaptic plasticity. J Neurosci 21:9744-9756.

Thomas MJ, Watabe AM, Moody TD, Makhinson M, O’Dell TJ (1998) Postsynaptic complex spike bursting enables the induction of LTP by theta frequency synaptic stimulation. J Neurosci 18:7118-7126.

Tohda M, Murayama T, Nogiri S, Nomura Y (1996) Influence of aging on rolipram-sensitive phosphodiesterase activity and $\left[{ }^{3} \mathrm{H}\right]$ rolipram binding in the rat brain. Biol Pharm Bull 19:300-302.

Tombaugh GC, Rowe WB, Chow AR, Michael TH, Rose GM (2002) Thetafrequency synaptic potentiation in CA1 in vitro distinguishes cognitively impaired from unimpaired aged Fischer 344 rats. J Neurosci 22:9932-9940.

Veng LM, Browning MD (2002) Regionally selective alterations in expression of the [alpha]1D subunit (Cav1.3) of L-type calcium channels in the hippocampus of aged rats. Mol Brain Res 107:120-127.

Wang H, Ferguson GD, Pineda VV, Cundiff PE, Storm DR (2004) Overexpression of type- 1 adenylyl cyclase in mouse forebrain enhances recognition memory and LTP. Nat Neurosci 7:635-642.

Weiss C, Preston AR, Oh MM, Schwarz RD, Welty D, Disterhoft JF (2000) The M1 muscarinic agonist CI-1017 facilitates trace eyeblink conditioning in aging rabbits and increases the excitability of CAl pyramidal neurons. J Neurosci 20:783-790.

Wu ZL, Thomas SA, Villacres EC, Xia Z, Simmons ML, Chavkin C, Palmiter RD, Storm DR (1995) Altered behavior and long-term potentiation in type I adenylyl cyclase mutant mice. Proc Natl Acad Sci USA 92:220-224. 